\title{
Mesenchymal stem cells provide novel insights into ankylosing spondylitis
}

\author{
Friedrich C. Luft $^{1}$
}

Published online: 21 December 2016

(C) Springer-Verlag Berlin Heidelberg 2016

Ankylosing spondylitis (AS), also known as Bechterew's disease or Marie-Strümpell disease, is an inflammatory disease primarily involving the joints of the spine and pelvis [1]. The cause is unknown; however, genetic factors, environmental triggers, and autoimmunity are all strongly implicated. The condition belongs to the "seronegative" forms of arthritis, since rheumatoid factor antibodies are not present. The disease is fairly common since as many as $1.8 \%$ of people are affected, men more so than women. Symptoms and signs generally begin in young adulthood. Pain and stiffness awaken the patients in the early morning hours. As the disease progresses, spinal mobility and chest expansion become increasingly impaired. AS can occur in any part of the spine or the entire spine, often with pain referred to one or the other buttock or the back of the thigh from the sacroiliac joint. About half of AS patients will also develop inflammation of the eye's anterior chamber, causing eye pain, redness, floaters, and sensitivity to light. This state-of-affair is believed to be due to the association that both AS and uveitis have with the HLA-B27 antigen inheritance. Prostatitis occurs with increased frequency in men. Cardiovascular involvement may include inflammation of the aorta, aortic valvular regurgitation, or disturbances of the cardiac electrical conduction system. Pulmonary involvement is characterized by progressive fibrosis of the upper lobes. In advanced stages of AS, a "bamboo spine" (Fig. 1 left) develops when the outer fibers of the intervertebral disks' fibrous rings ossify. This ossification causes

Friedrich C. Luft

friedrich.luft@charite.de

1 Experimental and Clinical Research Center, Max-Delbrück Center for Molecular Medicine and Charité Medical Faculty, Lindenberger Weg 80, 13125 Berlin, Germany the formation of marginal syndesmophytes between the adjoining vertebrae (Fig. 1 right).

The pathogenesis of AS is unclear [2]. About $90 \%$ of patients express the HLA-B27 genotype, indicating a strong genetic association, and individuals with the HLA-B27 genotype contract the disease more commonly than noncarriers. Specific autoantibodies have not been identified, although AS patients more commonly develop antineutrophil cytoplasmic antibodies (ANCA). The participation of CD8 and CD4 lymphocytes has been proposed, particularly since HLA-B27 appears to have a number of unusual properties, including possibly an ability to interact with $\mathrm{T}$ cell receptors in association with CD8+ cytotoxic T cells with HLAB antigen, as it is a MHC class 1 antigen. Although the fundamental AS triggers remain unknown, several lines of evidence implicate the cells and molecules in the pathway involving interleukin-23 and interleukin-17 [3, 4]. In mice, entheseal-resident (the connective tissue between the tendon or ligament and bone) $\mathrm{T}$ cells that are negative for both CD4 and CD8 and that respond to interleukin- 23 by producing interleukin-17 and other proinflammatory cytokines were shown to mediate peripheral and axial enthesitis, linking the interleukin-23-interleukin-17 pathway to the spondyloarthritis phenotype [5]. Dendritic cells from spondyloarthritis-prone HLA-B27 transgenic rats show numerous abnormalities, including impaired stimulation of $\mathrm{T}$ cell responses, cytoskeletal alterations, reduced expression of class II MHC molecules, enhanced apoptotic death, preferential induction of type 17 helper $\mathrm{T}$ cell expansion, and alteration of regulatory $\mathrm{T}$ cell function. Finally, even the microbiome is hypothesized to contribute to the pathogenesis of AS. Recent studies in children support this theory and studies in animals suggest that HLA-B27 may play a role in shaping the microbiome.

In this issue of J Mol Med, Xie et al. [6] present a novel approach to explore the pathogenesis of AS further. The 
Bamboo (cervical) spine
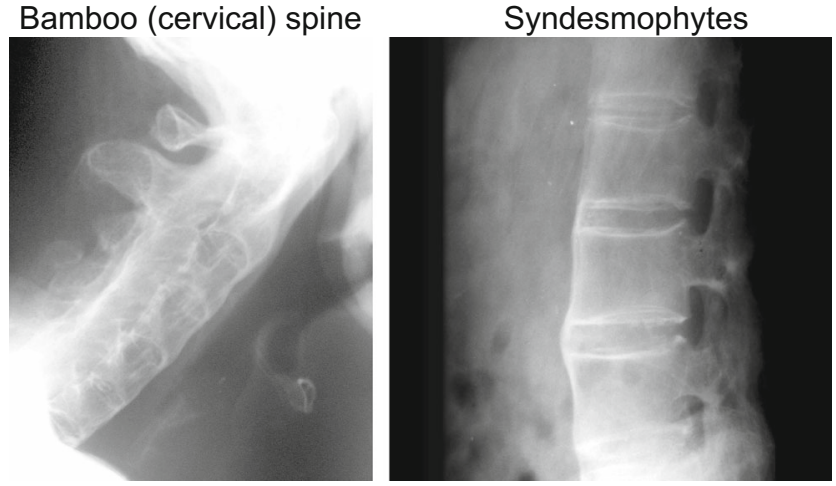

Fig. 1 Plain roentgenograms of a "bamboo" spine involving the cervical vertebra (left) and the development of syndesmophytes, an ossification process (right) (images taken from https://radiopaedia.org)

authors recruited 19 AS patients and 21 control subjects from whom they harvested bone marrow-derived mesenchymal stem cells (MSC) and peripheral blood mononuclear cells (PBMC). MSC are multipotent stromal cells that can be differentiated into a variety of cell types, including myocytes, adipocytes, chondrocytes, and osteoblasts. The authors showed earlier that because MSC secrete more bone morphogenic protein 2 (BMP2) but less Noggin, MSC from AS patients have greater facility for osteogenic differentiation than MSC from normal donors. The authors speculated that this state-of-affair could contribute to the underlying pathological osteogenesis in AS [7]. MSC are capable of synthesizing and excreting numerous substances, including monocyte chemoattractant protein-1 (MCP-1), also known as the chemokine (C-C motif) ligand-2 (CCL2). MCP-1 exhibits a chemotactic activity for monocytes and basophils. Important for this discussion is the fact that in bone, MCP-1 is expressed by mature osteoclasts and osteoblasts, under the control of nuclear factor $\mathrm{kB}(\mathrm{NF} \kappa \mathrm{B})$. In human osteoclasts, MCP-1 and the protein RANTES (regulated on activation, normal $\mathrm{T}$ cell expressed and secreted) promote human osteoclast fusion and rescue granulocyte macrophage colony-stimulating factor-induced suppression of osteoclast formation [8]. MCP-1 is implicated in pathogeneses of several diseases characterized by monocytic infiltrates, such as psoriasis, rheumatoid arthritis, and atherosclerosis. MCP-1 was identified as a biomarker candidate, distinguishing AS from mechanical low back pain with a sensitivity of $96 \%$ and a specificity of $83 \%$ in an earlier study [9].

Xie et al. [6] observed that MSC from AS patients secreted more MCP-1 during their abnormal osteogenic differentation than MSC from normal subjects. They identified extracellular signal-regulated kinase 1/2 (ERK1/2) pathway overactivation that they suggest is responsible for these findings. As a result, monocyte migration was increased, M1 macrophage hyperpolarization was observed, and AS patient-derived MSC secreted more MCP-1. Finally, abnormal osteogenic and tumor necrosis factor- $\alpha$ (TNF- $\alpha$ ) secretions were increased in the cells, compared to those in controls. Both an ERK1/2 inhibitor and the downregulation of MCP-1 in the MSC abrogated the observed effects. The authors speculate that MCP-1 triggers monocyte dysfunction during abnormal osteogenic differentiation of MSC from AS patients and propose the novel hypothesis that pathological osteogenesis leads to inflammation in AS. How could these issues be pursued further? More clinical studies would appear appropriate. Perhaps, when AS patients must be operated upon, affected tissue could be harvested in which MSC could be inspected while they are at work locally. MCP-1 is likely to be operative at the tissue level rather than functioning as a circulating cytokine. Perhaps such clinical studies could be coupled with improved imaging capabilities including 18F-fluoride PET/CT [10].

Not discussed by the authors is the potential of a specific MCP-1-directed therapy. For instance, Emapticap pegol (NOX-E36) is an L-RNA aptamer (trade name Spiegelmer®—-from German Spiegel "mirror"-by Noxxon Pharma) that specifically binds and inhibits MCP-1. The compound is an RNA-like molecule built from L-ribose units and functions as an artificial oligonucleotide named for being a mirror image of natural oligonucleotides. Due to their L-nucleotides, they are highly resistant to degradation by nucleases. Spiegelmers ${ }^{\circledR}$ are considered potential drugs and are currently being tested in clinical trials. In a recent human trial involving patients with type 2 diabetes mellitus and diabetic nephropathy, beneficial effects on ACR and $\mathrm{HbA}_{1 \mathrm{c}}$ were observed in an exploratory study that were maintained after cessation of treatment [11]. MCP-1 inhibition with emapticap pegol was generally safe and well tolerated. Emapticap may have disease-modifying effects in other MCP-1-driven conditions, including AS. Investigators have described development of spontaneous inflammatory disease in HLA-B27 transgenic mice expressing beta(2)m-free heavy chains on the cell surface [12]. Thus, potential animal models are also available to test the MCP-1 hypothesis.

Respectfully,

Friedrich C. Luft

\section{References}

1. Taurog JD, Chhabra A, Colbert RA (2016) Ankylosing spondylitis and axial spondyloarthritis. N Engl J Med 374(26):2563-2574

2. Mahmoudi M, Aslani S, Nicknam MH, Karami J, Jamshidi AR (2016) New insights toward the pathogenesis of ankylosing spondylitis; genetic variations and epigenetic modifications. Mod Rheumatol 18:1-12

3. Smith JA, Colbert RA (2014) The interleukin-23/interleukin-17 axis in spondyloarthritis pathogenesis: Th17 and beyond. Arthritis Rheumatol 66:231-241

4. Yeremenko N, Paramarta JE, Baeten D (2014) The interleukin-23/ interleukin-17 immune axis as a promising new target in the treatment of spondyloarthritis. Curr Opin Rheumatol 26:361-370 
5. Sherlock JP, Joyce-Shaikh B, Turner SP et al (2012) IL-23 induces spondyloarthropathy by acting on ROR- $\gamma \mathrm{t}+\mathrm{CD} 3+$ CD4-CD8- entheseal resident T cells. Nat Med 18:1069-1076

6. Xie Z, Wang P, Li J, Li Y, Wang S, Wu X, Sun S, Cen S, Su $\mathrm{H}$, Deng W et al (2016) MCP1 triggers monocyte dysfunction during abnormal osteogenic differentiation of mesenchymal stem cells in ankylosing spondylitis. J Mol Med. doi:10.1007 /s00109-016-1489-x

7. Xie Z, Wang P, Li Y, Deng W, Zhang X, Su H, Li D, Wu Y, Shen H (2016) Imbalance between bone morphogenetic protein 2 and Noggin induces abnormal osteogenic differentiation of mesenchymal stem cells in ankylosing spondylitis. Arthritis Rheumatol 68(2):430-440

8. Kim MS, Day CJ, Morrison NA (2005) MCP-1 is induced by receptor activator of nuclear factor- $\{$ kappa $\}$ B ligand, promotes human osteoclast fusion, and rescues granulocyte macrophage colony-stimulating factor suppression of osteoclast formation. $\mathrm{J}$ Biol Chem 280(16):16163-16169
9. Romero-Sanchez C, Tsou HK, Jan MS, Wong RH, Chang IC, Londoño J, Valle-Oñate R, Howe HS, Yu D, Leung BP et al (2011) Serum monocyte chemotactic protein-1 concentrations distinguish patients with ankylosing spondylitis from patients with mechanical low back pain. J Spinal Disord Tech 24(3):202-207

10. Idolazzi L, Salgarello M, Gatti D, Viapiana O, Vantaggiato E, Fassio A, Adami S, Rossini M (2016) 18F-fluoride PET/CT for detection of axial involvement in ankylosing spondylitis: correlation with disease activity. Ann Nucl Med 30(6):430-434

11. Menne J, Eulberg D, Beyer D, Baumann M, Saudek F, Valkusz Z, Więcek A, Haller H, Emapticap Study Group (2016) C-C motif-ligand 2 inhibition with emapticap pegol (NOX-E36) in type 2 diabetic patients with albuminuria. Nephrol Dial Transplant. doi:10.1093/ndt/gfv459

12. Khare SD, Lee S, Bull MJ, Hanson J, Luthra HS, David CS (2001) Spontaneous inflammatory disease in HLA-B27 transgenic mice does not require transporter of antigenic peptides. Clin Immunol 98(3):364-369 